\title{
HISTORIA E IDEOLOGÍA DEL EJÉRCITO REPUBLICANO IRLANDÉS (IRA). 1916-1998
}

Capítulo III

Iñaki Vázquez Larrea

Universidad Pública de Navarra

\section{EL LEGADO DE LAS HUELGAS DE HAMBRE:}

"¿Por qué nací en tierra de odios?. En tierra en la que el precepto parece ser: odia a tu prójimo como a ti mismo. Porque he vivido odiándome, porque aquí todos vivimos odiándonos"

Miguel de Unamuno,

El éxito de las Huelgas de hambre radicó en el hecho de que el IRA pudo justificar su lucha dentro de un contexto histórico más amplio. Le permitió fusionarse con el mito de una comunidad orgánica en eterna lucha contra Inglaterra. Al elenco de mártires como Tone, Emmet, Connolly o Pearse, habría que unir, a partir de ahora, los nombres de Bobby Sands, Hughes, Mc Creesh, O'Hara, McDonell, Hurson, Lynch, Doherty, McElwee y Devine. Tal y como Pearse profetizó, la sangre de los justos y los inocentes (encarnada en la figura de Bobby) sirve para mantener el vigor de un espíritu nacional que, generación tras generación, exige la muerte de jóvenes irlandeses en manos del opresor sajón. Ellos, como los patriotas fenianos en 1916, murieron por el exceso de amor patrio, al que hacía mención la poética de W.B. Yeats.

Desde un primer momento, la estrategia republicana trató de mostrar que la culpa de todo lo que sucedía en Irlanda del Norte, residía en el Parlamento de Westminster, en la Inglaterra obsesionada por sojuzgar a la rebelde Irlanda. Las Huelgas de Hambre, y la intransigencia del Gobierno de Thatcher, permitieron al movimientos republicano resituar en su propio léxico, el contexto del conflicto. Una confrontación exclusiva entre las fuerzas de liberación nacional (el IRA) y el colonialismo británico. Tal y como afirma Daithi O'Conaill: "La realidad es que diez hombres tuvieron la valentía de luchar por su país hasta el punto de dar sus vidas por él, y esa fue nuestra auténtica victoria. Demostramos al mundo que aquellos prisioneros representaban una lucha enraizada en Historia de Irlanda. La fortaleza moral y la hondura de las convicciones de estos patriotas echaban al traste toda la propaganda británica que los presentaba como criminales, como hooligans dementes. La lucha en los $\mathrm{H}$ - Block atrajo la atención del mundo entero. En Irlanda se tradujo en un reclutamiento masivo de jóvenes irlandeses en el movimiento republicano" (Padraig O'Malley, p. 273).

Las Huelgas de Hambre humanizaron la imagen de un movimiento que carecía de mártires, frente a la realidad cotidiana de bombas y asesinatos. La comunidad 
nacionalista revivió un profundo resentimiento anglófobo ante la humillación y muerte de nuestros hijos, que venía acompañada, a su vez, de una indiferencia absoluta ante el sufrimiento y el dolor de las acciones de nuestros hijos, provocaban en ellos, la comunidad protestante/Unionista. La particular relación amor/odio entre los católicos y el IRA, se desequilibró una vez más a favor del amor. Tras el martirio de Bobby Sands, la comunidad hablaba con respeto de los hijos de esa Nueva Irlanda que certificaban con su muerte, las virtudes de un nuevo paraíso terrenal prometido a los católicos de Irlanda del Norte. Muchos jóvenes católicos se enrolaron en las filas del IRA, queriendo emular y seguir el mensaje del nuevo Mesías del gueto, Bobby Sands. Mairead Corrigan, premio Nobel de la Paz en 1977, daba cuenta del trauma psicológico y del reverdecer del republicanismo radical en muchos enclaves católicos de Irlanda del Norte tras las Huelgas de Hambre: "Vi el funeral de Bobby Sands. Su féretro paró enfrente de mí jardín. Había decenas de miles de vecinos que meses antes se manifestaron en contra de la violencia paramilitar republicana y lealista dando un último adios a Sands. La gente de la comunidad sigue manteniendo vínculos familiares y emocionales con los presos en las cárceles. No se trata de que apoyen la violencia o al Provisional IRA. Ante todo se trata de muchachos que provienen de nuestra comunidad. Sabemos cómo y por qué han llegado a las cárceles. Cuando Bobby Sands murió, muchos de nosotros sentimos que aquello suponía volver a un punto de partida inicial. Diría que las Huelgas de Hambre abrieron una sima mayor entre católicos y protestantes. Si hoy por hoy hiciese un llamamiento a favor de la paz, y yo soy de Andersontown, nadie acudiría. Hay en muchas comunidades católicas un sentimiento de anglofobia que jamás había existido anteriormente. Mucha gente que nunca utilizó el término "británicos fuera", comenzó a utilizarlo entonces" (Padraig O'Malley, p. 268).

Por otra parte, las Huelgas de Hambre escapaban a la comprensión de los protestantes de Irlanda del Norte. Durante los 217 de Huelga, el IRA asesinó a 64 personas: 22 miembros del RUC (Royal Ulster Constabulary) y la UDR (Ulster Defence Regiment), 8 soldados británicos y 34 civiles, en su gran mayoría miembros de la comunidad Unionista. Cada asesinato se convertía en un símbolo, que reforzaba la mentalidad de sitio protestante. Los Huelguistas tenían elección, sus víctimas, que son nuestras víctimas, nunca la tuvieron.

Es más, la mística martirológica celta, y el espectáculo de hombres llevados al límite de la degradación personal e higiénica era una auténtica aberración moral para la ética calvinista de muchos protestantes del Ulster. La colusión de ética calvinista y mitología orangista reforzó todos los prejuicios que la comunidad Unionista anidaba con respecto a sus vecinos católicos. A sus ojos, reafirmaba la idea de que el martirio de aquellos chicos era un suicidio deliberado, producto de la maldad inherente a sus creencias y valores emanados de la Iglesia Católica romana y del nacionalismo irlandés, cuya simbología aparecía más nítidamente entrelazada que nunca durante las Huelgas de Hambre. El status de ciudadanos de segunda de los católicos, era por lo tanto auto inflingido. Producto de 10 erróneo de un sistema de valores moral, político y religioso inferior al protestante.

Para los Unionistas además, las Huelgas de Hambre invertían la noción victimista que el orangismo posee de la experiencia protestante en Irlanda. ¿̇Cómo es 
posible que los católicos, los enemigos de Dios y el Ulster, los enemigos de Irlanda del Norte, los mismos que trataron de aniquilarnos en 1641, los que pretendían matarnos de hambre en el sitio de Londonderry en 1689, los que traicionaron al Imperio en 1916, se victimecen de tal manera mientras están asesinando a miembros de nuestra comunidad? Para los protestantes aquella era una inversión vergonzante de su propia versión de Los Troubles, mientras el IRA continuaba con lo que para los protestantes no era sino una nueva matanza de San Bartolomé (masacre de hugonotes franceses en la Francia del siglo XVI). La versión lealista de las Huelgas quedó sintetizada en numerosas canciones que rememoran la incomprensión internacional y el sentimiento de aislamiento que la comunidad protestante experimentó en aquel periodo: "Esos mismos hombres que colocan bombas (el IRA)/ que nos asesinan/viven como animales/pero ese es su destino/viviendo en su sucia degradación día tras día".

O tal y como defendía el Arzobispo católico Robin Eames: " Por un lado tenías a los prisioneros republicanos y su idea de martirio redentor. Paulatinamente ganando más y más apoyo entre los católicos de Irlanda del Norte. Calles enlutadas, adornadas con banderas negras, disturbios, manifestaciones de protesta. Por otro lado tenías a la comunidad protestante diciendo: esto no es más que un suicidio, una muerte auto infligida que busca el chantaje político a nuestra comunidad. Es decir, por un lado la mística fatalista celta en torno a la idea de muerte, por otro la ética del trabajo protestante que les viene a decir que eres y tienes lo que te mereces. En la práctica Las Huelgas pusieron de relieve un profundo antagonismo comunitario que tiene que ver con la psique cultural y política de ambas comunidades" (Padraig O'Malley, p. 456).

La actitud del SDLP, dejando el camino abierto a la candidatura de Bobby Sands y de la propia Iglesia Católica, que se negaba a definir Las Huelgas en los mismos términos entendidos por la ética protestante (esto es, un suicidio sin paliativos), convenció a los protestantes de que todos los católicos eran enemigos de su Estado, de Irlanda del Norte, y de que el espectro político irlandés, sólo incluía diferentes gamas y variantes de republicanismo irlandés. En suma, las Huelgas de Hambre ahondaron en el abismo político y cultural que separa a ambas comunidades en Irlanda del Norte, y reforzó la mentalidad de sitio protestante, hostil, ahora más que nunca, a un acuerdo constitucional con los católicos.

Quién salió más fortalecido de las Huelgas de Hambre fue sin duda el movimiento republicano. Pasó de tener una faz meramente militar a tener una dimensión política mucho mayor. El Sinn Fein pasó de ser un hermano menor dentro del movimiento, a poseer un peso específico tan importante (o mayor) que el Ejército (el IRA). La ampliación del apoyo social dentro de la comunidad nacionalista y el nuevo flujo de voluntarios al IRA alimentaba todo tipo de ensoñaciones revolucionarias entre sus dirigentes. Si Danny Morrison se preguntaba en el Ard Fheis de 1981, si alguien podría discutir que con la urna en una mano y el fusil ( Armalite) en la otra, el movimiento no se haría con el poder en Irlanda. Adams se recreaba en el espejo revolucionario que James Connolly había diseñado antes de caer abatido por las balas de un pelotón de ejecución británico por su participación en la Rebelión de Pascua de 1916. La revolución, en su vertiente nacional y socialista, 
estaría al alcance de la mano si el Sinn Fein lograba un significativo apoyo político y social a ambos lados de la frontera irlandesa.

Se sentaron las bases de una nueva directriz estratégica. La denominada The Long War (la larga guerra), pretendía sostener niveles de violencia lo suficientemente elevados como para hacer entrever al Gobierno británico que la única alternativa a la resolución del conflicto pasaba por una retirada británica, "sickening the british", y por la reunificación política de la isla en forma de un Estado unitario de 32 condados.

Se preconizó, a su vez, una participación electoral como instrumento estratégico que a corto plazo desplazase al SDLP como principal fuerza política nacionalista en Irlanda del Norte, en beneficio del Sinn Fein, proceso que culminó con la ruptura de la tradicional política abstencionista en 1986. El Sinn Fein enviaría sus cargos electos a la República y participaría activamente en las elecciones de la provincia (Irlanda del Norte)'.

Para el Sinn Fein, el rédito electoral de las Huelgas de Hambre perduró hasta mediados de la década de los ochenta. En 1984, el IRA estuvo a punto de lograr asesinar a Margaret Thatcher en la Conferencia Anual del Partido Tory en Brighton, mientras que en las elecciones provinciales lograba hacerse con cerca del $45 \%$ del voto nacionalista. En febrero de 1985 era el propio IRA quien trataba de escenificar unas conversaciones en las que Hume parecería asumir los análisis republicanos sobre el conflicto irlandés.

Las conversaciones fueron recibidas con una mezcla de pánico e indignación por parte del Gobierno irlandés, pues parecían poner punto y final a la política de aislamiento que ambos gobiernos preconizaban para neutralizar la inusitada fortaleza del movimiento republicano en Irlanda del Norte. El Taioseach Garret Fitzgerald (Fine Gael) declaraba abiertamente su rechazo a cualquier diálogo con el movimiento republicano: "Dejemos claro, de una vez por todas, de qué tipo de gente estamos hablando. El IRA ha asesinado a más de 800 personas. La cifra incluye a miembros de fuerzas de seguridad nativas (los predominantemente protestantes RUC y UDR) que ejercían su labor a tiempo parcial. Ha provocado una réplica lealista que se ha cobrado la vida de 560 católicos. Han asesinado a gente inocente en el Reino Unido y en nuestro Estado ( la República de Irlanda). Han robado, secuestrado y asesinado sin piedad a miembros de la Gardai (policía de la República Irlandesa) y del Ejército Irlandés. No ocultan que uno de sus objetivos es acabar con nuestro Estado democrático e instaurar una dictadura militar, manteniéndose en el poder de la misma forma que asesinan y amenazan a todos sus oponentes políticos en Irlanda del Norte. En la República no queremos tener ningún tipo de relación con esta gente (Brendan O’Brien, p. 173).

Tanto el Gobierno británico como el irlandés, decidieron que era hora de asumir iniciativas políticas de forma conjunta sobre Irlanda del Norte. A finales de $1985 \mathrm{se}$ firma el AIA (Anglo Irish Agreement), más conocido por acuerdo Anglo/Irlandés. Dublín pasaría desde entonces a tener un rol consultivo en Irlanda del Norte, en especial en temas relativos a seguridad, y se forma una Conferencia Ministerial conjunta que tendría por objeto garantizar que un futuro acuerdo constitucional 
que facilitase la gobernabilidad del Norte de Irlanda, habría de contar necesariamente con el beneplácito de ambos gobiernos.

El AIA fue recibido con agrado por la comunidad nacionalista, no tanto por el rol consultivo de Dublín, sino por la furia y el enfado con la que la comunidad Unionista rechazó el acuerdo. Los nacionalistas veían, por primera vez, cómo Londres tomaba una iniciativa política lesiva para los intereses Unionistas, que consideraban el AIA como una intromisión inaceptable de la República en los asuntos de Irlanda del Norte. Los Unionistas respondieron en bloque con la campaña Ulster says no (El Ulster dice no), y la retirada de todos los parlamentarios Unionistas electos en el parlamento de Westminster.

Mientras tanto, el IRA se jactaba de haber utilizado más explosivos en 1985 que en todos los años de la campaña provo, y rechazó el AIA por legitimar la partición. Lo cierto es que el AIA tenía un claro matiz maquiavélico. Vehía a decir a los Unionistas que cuanto más reacios se mostrasen a un acuerdo Constitucional con los católicos, mayor sería el grado de intromisión de la República en Irlanda del Norte, y a los católicos que ambos gobiernos no eran sordos a sus aspiraciones políticas, esperando que ello minase el soporte social republicano en el Ulster.

\section{CONCLUSIÓN; EL LARGO ADIÓS A LAS ARMAS.}

Las consecuencias del AIA fue que el pez IRA empezó a perder agua dentro de la comunidad nacionalista. La estrella republicana comenzó a declinar en 1987. Aquel año, el IRA sufrió terribles reveses militares: a la cuenta de más de 20 activistas muertos entre 1987 y 1989, habría que sumar la abierta indignación, sin precedentes en toda Irlanda, por operaciones terroristas tan abiertamente sectarias y mal planificadas que llegaron a golpear la conciencia de muchos republicanos, que aún gustaban considerarse herederos del republicanismo liberal presbiteriano de Wolfe Tone.

A principios de 1987 la totalidad de la Brigada más letal del Sur de Armagh (área conocida en Irlanda del Norte por ser una República dentro de la República) fue abatida a tiros en una emboscada del SAS británico. En total, ocho activistas muertos. La perdida humana más grave del IRA en una sola operación militar desde 1920. El 8 de noviembre de 1987 el IRA asesinaba en Enniskillen a once civiles protestantes junto al Memorial of Remembrance Day (o Memorial del día de la Amapola), el día en que la comunidad Unionista honraba a los caídos por el Reino Unido. Similares dispositivos, que no llegaron a explotar, se encontraron en áreas urbanas predominantemente protestantes de Irlanda del Norte.

El intento por ultrajar el día más sagrado para los Unionistas de Irlanda del Norte resultó tan evidente que la Irlanda nacionalista, unionista, católica y protestante condenó al unísono lo que John Hume llegó a describir como "una salvajada vergonzosa" para todos los nacionalistas de Irlanda. La Iglesia católica irlandesa consensuó, por primera vez, un comunicado en la que se dirigía a los católicos de Irlanda en los siguientes términos: "Debe hacerse lo imposible para demostrar la repulsa católica ante estos crímenes, y disociar a la comunidad católica de todos aquellos que siembran la semilla del odio. No puede existir lugar para la 
ambivalencia. Ante la presente campaña de violencia republicana, la elección de todos los católicos es clara. Se trata de una elección entre el bien y el mal. Es pecaminoso formar parte de organizaciones comprometidas con la violencia. Es pecaminoso apoyar a estas organizaciones o hacer un llamamiento por parte de otras para que se les apoye" (Brendan O'Leary, p. 143).

En cierto modo, con la vía constitucionalista del movimiento republicano, sucedió como con Las Huelgas de Hambre. Una vez que se inicia su andadura es muy difícil abandonar sin perder grandes cotas de legitimidad política. Desde 1981 el movimiento republicano pasó de transferir la legitimidad de su lucha, de la Historia y de las tumbas de los fenianos muertos, al soporte electoral y social ofrecido por un amplio espectro de los católicos de Irlanda del Norte. Cuando Adams pasó a reconocer, en la década de los 90, que la lucha armada tenía una dimensión esencialmente propagandística, se le hacía cada vez más difícil no confrontar la realidad de que las atrocidades del IRA menguaban el mismo soporte social del que supuestamente emanaba la legitimidad política del movimiento. Al final el coste político de la lucha armada se mostró excesivo y contrario a los intereses del Sinn Fein.

Fue el propio Gerry Adams quien afirmo que "el movimiento republicano no puede permitirse otro Enniskillen"; lo que venía a aseverar es que, tarde o temprano, el movimiento republicano tendría que elegir entre el fusil y la urna, si quería sobrevivir como tal.

El IRA seguía siendo, no obstante, un instrumento de cohesión y reafirmación ideológica muy poderosa. Para muchos en el movimiento, la lucha armada era incluso más necesaria que nunca tras la debacle electoral sin precedentes de 1989. El SDLP capturaba ese año cerca del $70 \%$ del voto nacionalista en Irlanda del Norte. Las elecciones europeas fueron también un ruidoso fracaso para el Sinn Fein, humillado nuevamente por el SDLP, y el apoyo republicano en la vecina República de Irlanda, no pasaba del $1 \%$ del electorado.

Un año antes, en enero de 1988, las conversaciones Hume/Adams prefendían convencer a los republicanos de que una Irlanda Unida, sólo podía llegar de la mano de la política. Hume hacía constantes referencias al hecho de la nueva neutralidad británica sobre el mantenimiento de la Unión, y a que el propio Patrick Pearse se habría mostrado hostil a la lucha armada, si ello contribuía a dividir y a prolongar el sufrimiento del pueblo irlandés.

Es muy probable que Adams, ya por aquel entonces, estuviese convencido de la necesidad de guiar al movimiento al mundo del compromiso político, ante la evidencia del agotamiento de la estrategia de la larga guerra, pero reconocerlo en aquel momento, hubiera supuesto situarse ante el espectro de una nueva escisión (más grave que la de 1986) o ante una práctica implosión política similar a la acaecida tras la tregua de 1975.

Significativamente, el gobierno irlandés, a diferencia de 1985, mantuvo un silencio absoluto sobre las conversaciones Hume/Adams en 1988. Ante todo, porque teniendo lugar dos meses después de la matanza de Enniskillen, contribuyeron a engrandecer la figura política de Hume, que se dirigió de forma paternalista a los 
chicos descarriados de la misma tribu, y puso de manifiesto la desorientación y debilidad del movimiento republicano.

Pese a los varapalos políticos, el Sinn Fein se mantendría en un principio básico inmutable: mantener al IRA a bordo, para garantizar la cohesión del movimiento. Tras veinte años de resistencia, era obvio que el IRA no podía provocar la retirada británica, pero resultaba no menos obvio que el IRA no podía ser derrotado por vía militar. Aquella era la principal arma política que podía esgrimir el Sinn Fein.

Mientras tanto, la larga guerra seguía cobrándose víctimas. El 6 de marzo de 1988, Mairead Farrell, Séan Savage y Danny McMann, integrantes todos ellos de un comando del IRA, caen abatidos en una emboscada del SAS cuando se disponían a atentar contra una parada militar británica en Gibraltar. El discurso de Martin McGuinness ante la tumba de los ocho activistas muertos un año antes en Loughall, mayo de 1988, constituía un intento vano por resarcir la moral de un movimiento, que empezaba a mostrar claros signos de estancamiento y agotamiento. "El año pasado sufrimos una campaña sin precedentes por parte del Gobierno británico para acabar con el Ejército Republicano. Ha fracasado miserablemente. Porque mantengo la firme convicción de que las fuerzas republicanas, y su vanguardia armada, el Ejército Republicano Irlandés, poseen los medios y los recursos suficientes para derrotar a las fuerzas de ocupación británicas en los seis condados. No pretendo argumentar que el IRA tiene la capacidad de limpiar las calles de Belfast, Derry, Armagh o Antrim de soldados británicos, pero sí tiene la capacidad de desmoralizar a las fuerzas británicas de ocupación" (Brendan O'Brien, p. 189).

Los años venideros vendrían, precisamente, a poner en cuestión la capacidad real del IRA para desmoralizar a las fuerzas británicas de ocupación. En 1990, el IRA sólo conseguía asesinar a dos soldados británicos, la cifra más baja desde el inicio de su campaña, de un total de 19 personas muertas. Aquel mismo, las declaraciones del Secretario de Estado para Irlanda del Norte, Peter Brooke, reiterando que "el Gobierno británico no tiene intereses egoístas, estratégicos, económicos o de cualquier otra índole en Irlanda del Norte. Nuestro objetivo es animar, ayudar y facilitar un acuerdo constitucional", parecían querer poner en cuestión el dogma de fe republicano de que Inglaterra era el principal garante del veto Unionista, que impedía la reunificación política de la isla.

EI IRA parecía hacer caso omiso a las afirmaciones de Brooke, y renovó su ofensiva militar en Irlanda del Norte. El objetivo primordial de la nueva ofensiva se centró en áreas urbanas predominantemente protestantes. Se atacó sin remilgos el corazón de la comunidad Unionista. En 1991, el centro de Portadown (lugar de nacimiento de la Orden de Orange) era devastado por una bomba del IRA. Markethill y Tandragee siguieron el mismo destino. En enero de 1992, el IRA asesinaba a ochos trabajadores protestantes de Armagh, acusados de colaborar con las Fuerzas de la Corona (eran empleados en un Cuartel del Ejército Británico).

La estrategia política parecía pasar entonces por radicalizar a la comunidad unionista hasta tal punto, que hiciese inviable un acuerdo constitucional meramente interino, entre el nacionalista SDLP y el Unionismo oficialista del UUP (Ulster Unionist Party), mayoritario en la provincia. El objetivo era atraer al SDLP a un 
frente nacionalista común, en el que al menos, se garantizase la posibilidad de una Irlanda Unida a medio largo plazo, rompiendo así con el aislamiento del movimiento republicano. En el Ard Fheis (Conferencia Anual) de febrero de $1993 \mathrm{se}$ dejaban claros los términos de esta nueva estrategia. En concreto, Martin McGuinness habló al movimiento de la necesidad de "ser abiertos y flexibles, de la necesidad de tomar iniciativas dramáticas y dolorosas, reconociendo que los republicanos no tenemos todas las respuestas, pero sí algunas de ellas". En su discurso, McGuinnesss eludió mención alguna a la retirada británica, dejó abierta la puerta a "acuerdos interinos transitorios" entre ambas comunidades, y habló de la necesidad de un "proceso de reconciliación", que confrontase "Ios miedos unionistas".

Aquel Ard Fheis selló la tumba política de la Larga Guerra. Por primera vez, el Sinn Fein reconocía al Unionismo como parte central de un problema que es esencialmente irlandés, que no británico, saliendo, definitivamente, del autismo teológico en el que se venía desenvolviendo históricamente el movimiento. Se trataba entonces de copiar el modelo estratégico seguido Por el ACN (Congreso Nacional Africano). Es decir, garantía del inicio de conversaciones que facilitasen el alto el fuego del IRA, frente a la postura del Gobierno británico, básicamente opuesta, que pasaba por el decreto de un alto el fuego que posibilitase el inicio de conversaciones.

El guiño constitucionalista del Sinn Fein fue recibido con agrado por el SDLP y el Gobierno irlandés. El pre-acuerdo de una alianza política vino precedido por una relación simbiótica en lo que a discursos se refiere. Mientras que el SDLP asumía una constante retórica autodeterminista, el Sinn Fein hablaba de la necesidad de acomodar dos tradiciones nacionales en la isla: la católico/nacionalista y la Unionista/protestante, garantizando que ambas no volvieran a estar abocadas a un status de minoría.

El objetivo era reclamar conjuntamente el parity of steem, equidad Constitucional del nacionalismo irlandés en relación con el Unionismo en el seno de Irlanda del Norte, al tiempo que se desechaba cualquier acuerdo interino que no reconocieses la dimensión irlandesa del problema (esto es, vínculos institucionales con la República) en el marco de una línea estratégica concebida dentro de un proceso de 15 o 20 años, que culminaría con la retirada británica y la unidad de Irlanda.

El SinnFein jugaba ya más con los índices demográficos que con el Semtex. Indudablemente el retorno a un Estado Orangista era inviable, dada la tremenda fragmentación político/social de Irlanda del Norte desde la década de los setenta. Por otro lado, la homogénea comunidad católico/ nacionalista no podía considerarse ya nunca más como una minoría, cuando recientes censos demográficos la situaban en márgenes cercanos al $45 \%$ del total de la población norirlandesa.

El problema de esta teoría de "consenso" sobre la base de acuerdos interinos, es que los Unionistas pueden sumarse a ese "consenso" siempre y cuando finalmente éstos digan sí a una Irlanda Unida, pero al parecer el "consenso" no parece tan claro si los Unionistas optan por decir no a una Irlanda Unida. El nacionalismo 
irlandés parece poco dispuesto a desvincularse, definitivamente, de un determinismo historicista de clara raigambre antidemocrática.

Sea como fuere los acuerdos Adams/Hume de abril de 1993 fueron remitidos a la Opsahl Commission (Comisión internacional independiente para la resolución del conflicto en Irlanda del Norte) y al Gobierno irlandés, que los definió en palabras del ministro de Asuntos Exteriores Dick Spring, como un Covenant nacionalista (pacto nacionalista) cuya virtud esencial era el reconocimiento de la legitimidad, como iguales, de ambas tradiciones nacionales, tanto en el contexto de Irlanda del Norte, como en el más global de la isla de Irlanda.

Los términos y el léxico del acuerdo permitían, además, a Adams y a McGuinness poder hacerlo vendible a las bases del movimiento, de la siguiente forma: "Es cierto que no hemos conseguido la victoria militar, pero sí la igualdad con respecto a nuestros enemigos, los Unionistas y el Imperio Británico. Lo que no han podido hacer los voluntarios (el IRA) en treinta años, lo haremos nosotros, los "revolucionarios pragmáticos" (término acuñado por el histórico miembro del IRA Brian Keenan) en quince años.

El Sinn Fein insistía en la necesidad de que el Gobierno británico persuadiese a los unionistas de que entrasen en un marco de negociaciones pre-establecido por la reciente alianza nacionalista. Persuasión que los Unionistas concibieron como abierta coacción cuando una bomba del IRA sesgaba la vida de nueve civiles protestantes en el bastión lealista de Shankill Road (Belfast Oeste). La imagen de Adams junto al féretro del activista del IRA muerto por su propia bomba en Shankill, exaltó aún más las iras Unionistas.

Tanto la UDA (Ulster Defence Association) como la UVF (Ulster Volunteer Force) clamaron venganza. Una semana después, siete católicos eran asesinados en Greysteel (Derry) en un atentado reivindicado por la UDA. Desde 1992 los paramilitares lealistas venían superando al IRA en capacidad letal, y octubre de 1993 pasaría a ser recordado como el mes más sangriento de Los Troubles, desde 1976. Irlanda del Norte se deslizaba, una vez más, por la pendiente de la violencia sectaria.

Ante tal situación, ambos Gobiernos decidieron recuperar la iniciativa política. El Primer Ministro Albert Reynolds y el británico John Major hicieron pública, el 15 de diciembre, la Declaración de Downing Street. Un principio de acuerdo para alcanzar la paz con seis puntos esenciales:

-Reconocimiento del derecho del pueblo de Irlanda a ambos lados de la frontera de determinar libremente, sin coacción alguna, su propio futuro, lo que debería conducir en condiciones ideales a la posibilidad a largo plazo de la unidad política de la isla.

-Posibilidad de desarrollar nuevas estructuras de Gobierno para Irlanda del Norte y de encontrar fórmulas que mejorasen las relaciones entre el Norte y el Sur de la isla, por un lado, y entre las dos islas por otro.

-Invalidez de cualquier acuerdo futuro que comportase un cambio en el status actual de Irlanda del Norte, sin el consentimiento de la mayoría de su población. 
-Necesidad de que tal consentimiento incluyese el reconocimiento de la libertad de los Unionistas de negarse a aceptar todo cambio que no fuera alcanzado por cambios democráticos.

-Compromiso del Gobierno irlandés de involucrarse en dicho consentimiento, ofreciendo a los grupos paramilitares la posibilidad de sentarse en la mesa de negociaciones previa renuncia expresa a la lucha armada.

-Declaración expresa del Gobierno británico de no tener ningún interés estratégico y económico en Irlanda del Norte y adquisición, por el mismo, del compromiso de impulsar y permitir la consecución del acuerdo.

La Declaración, en principio, no fue rechazada de plano ni por los republicanos, ni por gran parte de la comunidad Unionista (a excepción de Paisley, que lo calificó como una traición al Ulster y a la Unión). El 31 de agosto de 1994 el IRA declaró un alto el fuego indefinido dando por bueno el marco de acuerdo pre-establecido por la Declaración. Pocas semanas después la UDA y la UVF hacían lo propio.

Se abría un periodo de conversaciones multipartidistas (multi party talks), que chocaron la exigencia Unionista y británica de que el alto el fuego debería abrir inmediatamente un proceso de desarme del IRA y los grupos paramilitares lealistas. El movimiento republicano argumentaba que una desmilitarización conjunta (que incluiría una reforma del RUC y una reducción significativa de tropas británicas) sólo podría ser posible, en todo caso, tras la firma de un Acuerdo. El impasse abierto por este nuevo escollo negociador comenzaba a ser interpretado en el seno del IRA como un intento deliberado de llevar a todo el movimiento a un callejón sin salida, a una lenta agonía, similar a la de la tregua de 1975. Muchos voluntarios consideraban, además, que la exigencia del desarme tras treinta años de guerra, significaba validar una rendición, una capitulación humillante, frente a los británicos y los Unionistas. La respuesta del IRA no se hizo esperar. El 9 de febrero de 1996 una bomba devastaba el centro financiero londinense, matando a dos personas. El IRA había roto el alto el fuego.

En este contexto, la mediación del Senador norteamericano George Mitchell resultó providencial. Logró que todos los paridos norirlandeses firmasen una carta de seis puntos sobre la base del rechazo a la violencia como instrumento de acción política y el mantenimiento de conversaciones para alcanzar un acuerdo de consenso entre todas las fuerzas políticas, Unionistas, lealistas, nacionalistas y republicanas. El Sinn Fein se comprometió a respetar todos los puntos en su integridad. El DUP de lan Paisley era el único partido que permanecía fuera del proceso de paz.

Al mismo tiempo, Mitchell puso el proceso de desarme en manos de una Comisión Independiente liderada por el General canadiense John de Chastelain. Tal decisión permitía congelar la polémica suscitada por el espinoso tema del desarme, otorgando un margen de tiempo mucho mayor al proceso, garantizando, a su vez, la posibilidad de reanudar conversaciones multipartidistas si el IRA declaraba un nuevo alto el fuego. 
El 19 de julio de 1997 el IRA declaraba un nuevo cese indefinido de la violencia. Se abría una nueva ronda de conversaciones entre partidos, que desembocó en la firma del Acuerdo de Viernes Santo el 10 de abril de 1998. El acuerdo preveía la articulación de una Asamblea Autónoma con un Ejecutivo coaligado (Power Sharing Executive), con representantes de ambas comunidades, un Consejo de las Islas (entre los distintos Estados y autonomías de las islas británicas), e instituciones comunes entre la República e Irlanda del Norte.

Finalmente, tras los Acuerdos de San Andrés (2004) y el desarme del IRA en el año 2005, el Sinn Fein, como principal fuerza nacionalista en el Ulster, se pliega a un acuerdo de mínimos con el DUP de lan Paisley para liderar una sociedad en transición, que guarda muchas similitudes con los Acuerdos de Sunningdale de 1973 (el propio Seamos Mallon, número dos del SDLP, definió el Acuerdo de Viernes Santo como un Sunningdale para tontos) .Un acuerdo al que, recordemos, podría haberse sumado con un coste humano muchos menor, 3.000 muertos desde entonces, hace más de cuatro décadas. (Michael Murray, p. 78).

\section{BIBLIOGRAFÍA:}

ADAMS. G., (1986), The Politics of Irish Freedom, Dublín, Dingel

BELL. B., (1994), Ideology and The Irish Question (UIster Unionim and Irish Nationalism 1912-1916), Oxford, Clarendon Press.

BERESFORD. D., (1994), Ten Men Dead, London, Harper Collins.

BISHOP. P., (1987), The Provisional IRA, London, Corgi Books.

BOWYER. B., (1970), A History of the IRA (1916-1970), London, Anthony Blond Ltd.

COOGAN, T. P., (1971), The IRA, London, Fontana Books.

DEVLIN, P., ( 1995), Straight Left (An Autobiography), Belfast, The Blackstaff Press.

EIRE NUA, Provisional Sinn Fein, octubre, 1971.

FOSTER, R.F., (1989), Modern Ireland (1600-1972), London, Penguin Books.

MITCHELL, P., (1999), Politics in Northern Ireland, Belfast, Westview Press.

MURRAY, M., (2005), Northern Ireland After The Troubles: A society in transition, London, Paperback.

O'BRIEN, B., (1997), A pocket History of the IRA, Dublin, The O'Brien Press.

O'BRIEN, B., (1993), The Long War (The IRA and Sinn Fein), Dublin, The O'Brien Press. 
O'DOHERTY, M., (1998), The Trouble with Guns (Republican Strategy and The Provisional IRA), Belfast, The Blackstaff Press.

O'BRADAIGH, R., (1973), Our People, Our Future, Dublin, Dingel.

O'LEARY, B., (1996), The Politics of Antagonism (Understanding Northern Ireland), London, The Athlone Press.

O'MALLEY, P., (1990), Biting at The Grave (The Irish Hunger Strikes and The Politics of Despair), Boston, Bacon Press.

O'MALLEY, P., (1997), The Uncivil Wars (Ireland Today), Boston, Beacon Press.

PATTERSON, H., (1997), The Politics of Illusion (A Political History of the IRA), London, Serif.

SHIRLOW, P., (2006), Belfast (Segregation, Violence and The City), London, Pluto Press.

SMITH, M.L., (1995), Fighting for Ireland? (The Military Strategy of the Irish Republican Movement, Routledge, London.

TAYLOR, P., (1997), Provos (The IRA and Sinn Fein), Bloombury, London. UNAMUNO, M., (1998), Abel Sánchez, Madrid, Cátedra.

\section{IÑAKI VÁZQUEZ LARREA}

Doctor en Antropología. 


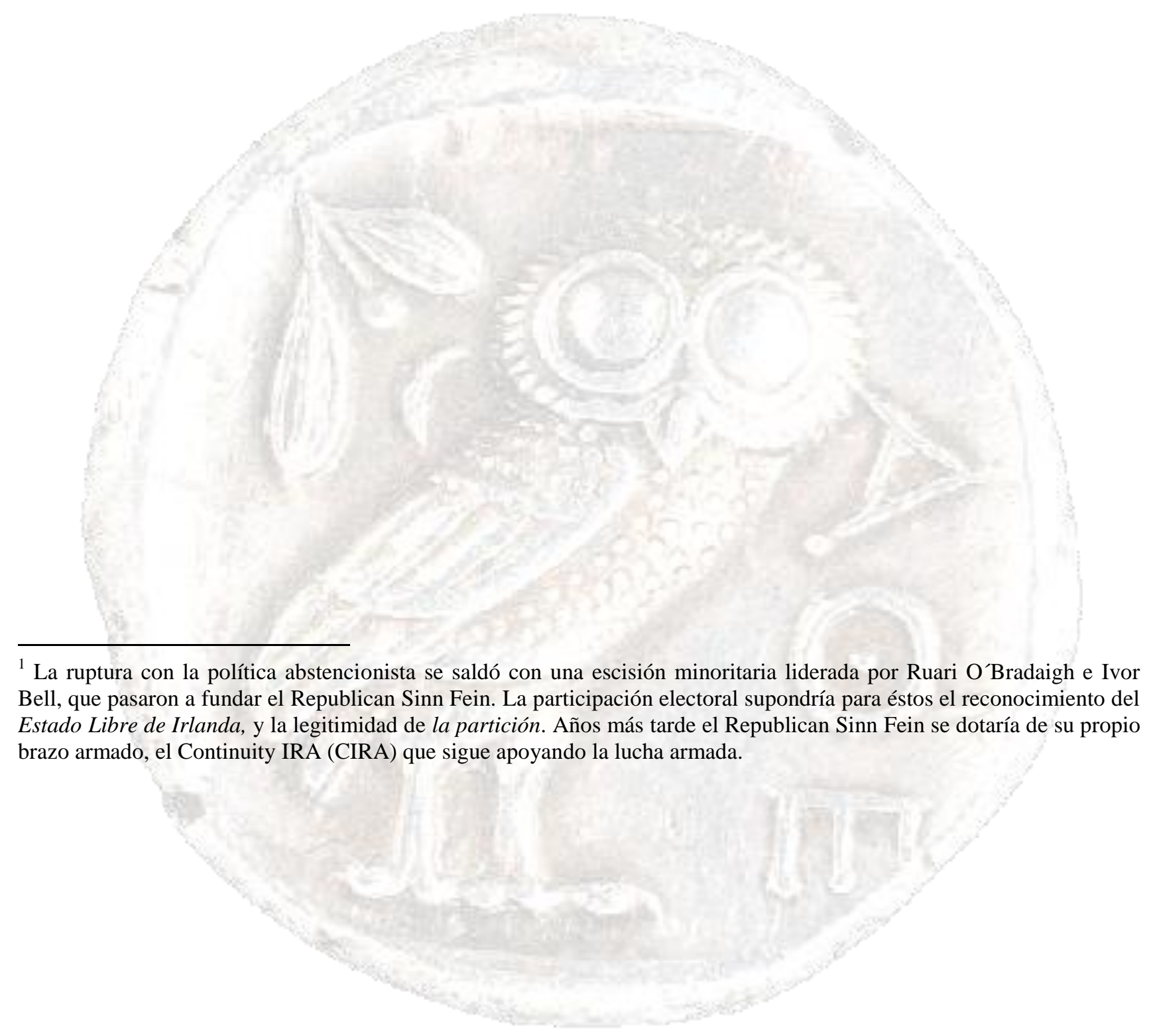

